\title{
INFANCIAS DES-ALOJADAS \\ Efectos subjetivos en niños alejados de sus familias y \\ de su entorno social y cultural
}

\section{CHILDHOODS E-VICTED \\ Subjective effects on children transferred distant from their families and socio-cultural enviroments}

\author{
Diego Peralta**
}

A quien en este escrito nombré como Jonatan, a sus intentos por adueñarse de su historia, y a su fortaleza, que aunque admirable, no pudo evitar que su vida se le escape, poco tiempo después de nuestra despedida.

\section{Resumen}

En el presente artículo se analizarán los efectos subjetivos en niños y adolescentes trasladados a centros residenciales ${ }^{* * *}$ distantes de su ciudad de origen, a partir de la aplicación de una Medida de Protección Excepcional.

Se propone interrogar los efectos subjetivos del incumplimiento de los tiempos legales, enunciados en la Ley $12.967^{* * * *}$, por parte de los organismos e instituciones res- ponsables de hacerlos cumplir, en desmedro del Interés Superior del Niño.

Palabras Clave: Infancia - instituciones de alojamiento - identidad.

\section{Abstract}

This article will analyse the subjective effects on children and adolescents transferred to residential centers distant from their place of origin following the implementation of

\footnotetext{
* Este artículo fue escrito sobre la base del Trabajo Integrador Final de la Carrera de Psicología Clínica, Institucional y Comunitaria, cohorte 2012-2014. La dirección estuvo a cargo de la Dra. Silvia Lampugnani.

** Psicólogo, Especialista en Psicología Clínica, Institucional y Comunitaria. U.N.R.; Maestrando en Infancias e Instituciones, UNMDP; psicoanalista; integrante de Punto de Encuentro Familiar-Rosario

*** Alternativamente se irá utilizando la expresión centro residencial u hogar para varones de acuerdo al contexto. El primero remite a la formalidad institucional y el segundo, al nombre por el cual es reconocida la institución en la localidad y por los propios niños.

**** Legislatura de la Provincia de Santa Fe. (2009) Ley 12.967. Promoción y Protección Integral de los Derechos de las Niñas, Niños y Adolescentes.
} 
an Exceptional Protection Measure.

We put a question mark over the subjective effects of the failure to comply with the legal time limits laid down in Law 12.967 by the agencies and institutions responsible for enforcing it, in detriment of the Best Interests of the Child.

Keywords: Children - Residential Facilities - Identity.

\section{Introducción}

Durante la residencia de la carrera de especialización, realizada en un Centro de Atención Primaria de Salud en una localidad del interior de la provincia de Santa Fe, se recibieron en el área de psicología a un niño y un adolescente oriundos de Rosario, que, debido a la aplicación de una medida de protección excepcional, se encontraban alojados en un hogar para varones.

A partir de esta situación, se fueron observando los efectos de la cronificación del alojamiento en la localidad que los recibe y del consecuente distanciamiento de su centro de vida.

Durante los dos años que duró la residencia, se realizaron entrevistas con los profesionales implicados en la situación de alojamiento de ambos niños. A partir de allí se construyó una problemática con dos dimensiones en juego: por un lado, los efectos del alejamiento de los vínculos familiares primarios y, por otro, la rápida conformación de lazos vinculares con las distintas instituciones de la localidad de destino.

Esta problemática se produjo debido a que los procesos de intervención burocrática que atraviesan los niños afectados por una medida de protección excepcional los llevan a permanecer durante años en una institución de alojamiento transitorio que consecuentemente, deviene su centro de vida.

Por lo tanto, podemos describir un cambio rotundo en la vida de estos niños. Si su centro de vida fue valorado por los agentes del Estado como de vulnerabilidad de sus derechos, se desprende que el fin de la toma de la medida excepcional sería terminar con la situación de vulnerabilidad y reintegrar derechos. Pero, ¿se pueden tomar medidas de protección excepcional sin que a su vez otros derechos no corran riesgo o directamente sean, a su vez, vulnerados, como ser el interés superior del niño a no ser apartado de sus referencias culturales y familiares?

Las pequeñas localidades donde estos niños o adolescentes son alojados, mantienen una lógica de reconocimiento del otro. El recorrido por gran parte de las instituciones de la comunidad va generando una acogida, incorporándolos y dándoles un lugar rápidamente. Más allá de los prejuicios que algunas nominaciones puedan acarrear, la presencia del otro, en el caso de estos niños $\mathrm{y}$ adolescentes, no es invisible.

El discurso institucional del hogar promueve la conformación de lazos con la comunidad que aloja y rechaza implícitamente el contacto con la familia de origen, ubicándolo como desorganizador de la estadía de los niños en la institución, obstaculizando la incorporación de las normativas institucionales.

Los niños pagan su pertenencia a la institución silenciando su pasado. En este quedar relegados de sus lazos primarios, logran construir identificaciones momentáneas y se apropian pasivamente de su nuevo lugar, 
adaptándose. La Dirección Provincial de Niñez, Adolescencia y Familia (en adelante la Dirección de Niñez) sostiene un discurso de continuidad con los lazos familiares primarios, pero el devenir del tiempo termina favoreciendo el discurso de la institución que aloja a los niños y que, en este punto, va en dirección opuesta al discurso estatal.

Desde este lugar nos preguntamos qué concepción de infancia se puede leer en las intervenciones que se realizan sobre estos niños, donde los posicionamientos institucionales, desde la Dirección de Niñez, el discurso jurídico, y los centros residenciales, entran en contraposición, manteniendo a los niños afectados por una medida excepcional, entrampados en una anomia jurídica.

Los niños a quienes hacemos referencia, llegan a los hogares sin que la persona que los reciba conozca su historia; son niños que cargan con su propia historia, sin que haya otro que pueda acompañarlos en la construcción de un relato que incluya sus vivencias identitarias previas a la medida excepcional.

¿Qué referencias pueden sostener a los niños que son trasladados a hogares transitorios, sin un relato de su historia que los acompañe?

¿Qué sucede cuando la espera va dando lugar al descreimiento, cuando la posibilidad de fantasear un futuro va quedando incierta? ¿Se espera que un niño pueda pensarse a sí mismo, que se imagine un futuro, sin que otro haya deseado y sostenga un futuro deseado para ellos?

El espacio clínico con estos niños posibilitó un armado discursivo que les permitió reconstruir su historia de vida, generando la posibilidad de imaginar un futuro que incluyera sus rasgos identitarios.

La reconstrucción biográfica de la que se dará cuenta en este trabajo es parcial y fragmentaria. Tanto el nombre como las referencias de los niños fueron modificados arbitrariamente para preservar su identidad, en especial resguardo de la confidencialidad.

\section{Alojamiento y hospitalidad}

Luego de la aplicación de la medida de protección excepcional, el centro residencial recibe al niño sin una historización por parte del equipo interviniente. $\mathrm{El}$ niño o niña es recibido y se busca el modo de que se adapte a la institución. Así, se genera un tiempo fuera de toda cronología anticipada.

¿Cuáles son los procesos filiatorios que ofrecen estos lugares? Estas instituciones en muchas situaciones intentan despojarse de la característica de hogar, asemejándolos más a una institución homogénea impersonal, sosteniéndose paradójicamente en lo que plantea la ley como lugar transitorio, cumpliendo con los tiempos supuestamente breves, acordes con lo establecido.

Al momento de la aplicación de la medida excepcional, la Dirección de Niñez busca, para trasladar a los niños, el lugar de alojamiento que se encuentre con plazas disponibles. Cuando el niño se instala en la institución, la vorágine de las urgencias que ocupan a la Dirección genera que se detenga o se anule la intervención sobre la situación problemática del niño, y comience una estadía sin tiempos precisos, alejados de los 90 días previstos por la Ley 12.967.

El hogar ofrece un espacio y se ponen de manifiesto las reglas a las que el niño tiene que adaptarse, donde lo que se toma en 
cuenta es el comportamiento (si se adapta o no a la institución), frente al diagnóstico situacional del niño alojado (teniendo en cuenta su historia y recorrido).

Uno de los objetivos principales del discurso de las políticas en niñez, que se asienta en la mencionada ley 12.967 es el retorno de los niños a sus centros de vida, buscando realizar en ese lapso intervenciones tendientes a reconstruir un lugar de apoyo en el territorio social y familiar donde se encuentran sus lazos. Visto esta posibilidad como inaccesible en la mayoría de las circunstancias, la estadía en la institución se vuelve la opción más probable.

Una medida de protección excepcional intentaría reinstalar derechos que estaban siendo vulnerados. Luego de un periodo de tiempo, cuando no se llevan a cabo las medidas tal como se fundamentan, ni se cumplen los tiempos preestablecidos, es el Estado quien, por acción u omisión, coloca al niño fuera de la legalidad que el mismo Estado intentaba restablecer. Se produce, entonces, una vulneración de derechos mucho más silenciosa que la que existía previa a la toma de la medida de protección excepcional, dado que el Estado queda fuera del lugar de tercero de apelación.

\section{Posiciones subjetivas frente al desa- rraigo}

Jonatan y Andrés son un adolescente y un niño que en distintas circunstancias llegaron a un hogar para varones de una pequeña localidad santafesina. Jonatan llegó a los once años, fue trasladado con su hermano y su hermana, mientras que Andrés llegó a la edad de seis años; este último también fue trasladado a esta localidad con una hermana adolescente, la cual al poco tiempo se escapó del hogar de niñas y volvió a Rosario, donde comenzó a transitar distintos hogares y modos de alojamiento.

El hogar para varones les dio un lugar, los recibió, les brindó las condiciones que les permitieron permanecer allí por años, transitando las instituciones clásicas de la localidad. Ambos pudieron tomar ese lugar, dejando afuera algo de lo que traían en cuanto a historia, cultura y entorno social. La medida de protección excepcional implicaba que debían cortar con algo, dejar algo, pero como todo corte, no se puede precisar el lugar por donde acontece.

El centro residencial que los alojó es coordinado por un grupo de mujeres que realizan esta actividad ad-honorem. Se trata de una asociación civil que recibe subsidios por parte del Estado y gestiona otros gastos a partir de actividades para recaudar fondos.

En lo formal, la institución es dependiente de la Dirección de Niñez, aunque el distanciamiento en la comunicación cotidiana termina generando que las intervenciones sean decididas por la comisión directiva del centro residencial.

La posición hegemónica que se detecta en el hogar para niños es muy compleja, ya que los recibe y aloja. Los niños expresan su conformidad, y en la cotidianeidad se instituye como una gran familia. Las coordinadoras son llamadas por los niños "tías" y las cuidadoras, "mamis".

Si bien la Dirección de niñez nunca recibió quejas ni denuncias sobre esta institución, e incluso se manifiesta muy conforme con el trabajo; es la propia institución la que plantea conflictos cuando aparece un 
vínculo con la familia del niño alojado, los referentes del hogar califican la situación como peligrosa o desorganizadora, desconociendo los derechos del niño a continuar en contacto con su familia. Pareciera que esto no es tenido en cuenta por la Dirección al momento de evaluar el trabajo del hogar, aunque en su discurso aparezca la continuidad de contacto con la familia como uno de sus propuestas de trabajo.

El modo de alojar del hogar deviene homogeneizante, no implica un intento de diferenciación en cuanto a su origen o la vida y cultura que llevaban hasta ese momento, sino que exige la adaptación a nuevas reglas, un modo de alojar condicionado.

\section{Historia de vida, la escisión del relato}

Las historias de Jonatan y Andrés se unen y se diferencian. Entre ellos decidieron armar un lazo, que intenta inscribirse con ciertas dificultades. Andrés fue bautizado durante su estadía en el hogar y eligió como padrino de bautismo a Jonatan, quien aceptó ese lugar, sin saber muy bien cómo ocuparlo.

Jonatan buscaba y ensayaba modos de posicionarse en torno a esta figura de padrino. Desde este nuevo nombramiento, tímidamente intentaba acompañarlo, jugar con él. Incluso, le ofreció dinero que recibía de su pensión para un viaje que Andrés realizaría con la escuela.

Andrés y Jonatan pudieron permanecer por mucho tiempo en el hogar. Esto implica que pudieron adaptarse, lograron encuadrarse dentro de las condiciones que la institución y esta localidad les proponían para poder permanecer.

Comenzaron a concurrir casi al mismo tiempo al área de Psicología del centro de salud local; la demanda provino del hogar, debido a algunas conductas poco adaptadas. A partir de allí, los referentes del hogar comenzaron a decir mucho más que lo que Andrés y Jonatan podían expresar en un principio. Pero ese decir de la comisión directiva, no estaba referido tanto a Jonatan y a Andrés en particular, sino a los entramados interinstitucionales que deciden sobre los niños y adolescentes, sin poder hablar específicamente de los niños.

Jonatan y Andrés mostraban un proceso de adaptación muy efectivo en un principio, pero que en algún punto dejaba entrever que en su decir permanecía como encerrado algo que ocultaban; el relato, en lo explícito, se oía como si su historia comenzara el día que llegaron al hogar. Ellos y los referentes institucionales enmudecían frente al relato de sus vidas previas. Solo se podía oír algún acontecimiento de sus historias en alguna reunión en la Dirección de Niñez, donde alguna carpeta contenía escrita la situación descriptiva de un niño en el contexto en el que fue tomada la medida, relato que no continuaba más allá del momento preciso de la toma de la medida excepcional. La carpeta constituía una respuesta a una demanda administrativa y no un relato que incluyera al niño en relación a su identidad e idiosincrasia.

La historia de este niño y de este adolescente quedaba dividida en dos, y ellos solo hablaban de su presente.

¿Cuál es la relación entre esta adaptación, por momentos demasiado lograda y ese relegar al silencio parte de su historia?

El reencuentro con la propia historia aparecía de manera fragmentaria, a retazos, cuando se hacía presente alguna conexión 
que los devolvía allí, un familiar que los visitaba, un viaje a Rosario, algún movimiento que los sacaba de la continua estancia.

\section{El lenguaje como último refugio}

Jonatan era alto, alegre, despierto; su estadía cronificada en esa pequeña localidad lo convirtió en un adolescente querido y popular. Las instituciones se abrieron y permitieron la conformación de lazos, organizando una filiación que le permitía un modo de estar sostenido en el tiempo.

Se ubicó rápidamente en esta localidad, se acomodó a su dinámica, a las calles, las instituciones, los clubes. Encontró algo allí y lo pudo hacer consistir.

El pedido al área de psicología estaba relacionado con cambios en su comportamiento después de haber pasado un fin de año en Rosario con parte de su familia. El viaje movilizó algo y la institución de alojamiento se vio conmovida en uno de los puntos de mayor temor: Jonatan se mostró desadaptado. En esas circunstancias, Jonantan comenzó a asistir a los encuentros en el centro de salud.

Primero se realizaron entrevistas con la institución y, luego, asistió Jonatan. Desde un comienzo quiso ir a las entrevistas, proponía jugar al truco constantemente, era difícil precisar el motivo de su interés por el espacio.

En un momento, sin embargo, expresó algo diferente, se sonrió generando desconcierto en quien lo estaba escuchando ¿Qué le produjo esa sonrisa? Mencionó que había descubierto en el hablar del analista un rasgo de la localidad donde se encontraba. Muchas veces, a los que son originarios de algunos pueblos del interior, los rosarinos les señalan que terminan algunas frases agregándole la palabra pero al final. El analista era de esa localidad en la que él se encontraba y luego se trasladó a Rosario. Jonatan comenzó a encontrarse con ese rasgo en esa localidad y en ese momento lo encontró en quien lo escuchaba. Sabía que el analista vivía en Rosario, pero que había nacido en la localidad donde él, ahora, vivía. El lazo transferencial comenzó a tomar un rasgo que hacía huella en el ida y vuelta de Rosario. De alguna manera establecía en las sesiones un decir sobre Rosario, lo que implicaba un decir sobre su historia.

Algo lo hizo hablar, decir otra cosa, pero necesitó un soporte, lo que preguntó o marcó es justamente donde él se pudo ver y escuchar, conformando por momentos un discurso del cual poder volver y plantear un lugar propio, retomar los significantes que lo nombran, de manera invertida.

Surgió un interrogante ¿Cómo poder poner a disposición algo de ese soporte que le permitió hablar?

Encontró algo en esa localidad, y, a la vez, a alguien que, inversamente, encontró algo en Rosario y se lo ofreció discursivamente. En un momento, el relato viró hacia el río Paraná. A partir de allí comenzó a hacer un relato sobre su familia, cuyos miembros, en su mayoría, eran pescadores. Contó sobre la técnica para pescar con redes, se sirvió de un lápiz y un papel para dibujarlo, habló sobre la correntada, el tamaño de las redes y el tamaño de los peces, de su saber sobre el río. Se asombró al reconocer que nadie, en la localidad donde se encontraba alojado, sabía que él había sido pescador. Nunca había hablado de eso. 
En ese momento algo del pasado de Jonatan comenzó a reubicarse como recuerdo, no porque haya estado suprimido, sino porque en esa lograda adaptación eficiente había dejado algo atrás, como pérdida frente a la demanda institucional. Había olvidado su pasado, relegándolo al silencio.

Para poder realizar ese recorrido, para poder construir un relato, Jonatan necesitó encontrar una diferencia, para, a partir de allí, nombrarse.

Alguien que viene de afuera, de un afuera que es a la vez lo más propio, lo más íntimo, le permite descubrir en la lengua un detalle que lo vuelve extranjero de la pronunciación del otro, para luego poder encontrarse en esa diferencia.

Jonatan podía adaptarse, pero no llegaba nunca a ponerle el pero al final de la frase. ¿Podemos pensar este punto como un refugio donde guardaba su no pertenencia a esa localidad?

A partir de allí se abrieron relatos distintos en relación a su vida en Rosario. Uno de ellos tenía que ver con el fútbol. Su padre lo llevaba de niño a la cancha y su pasión por el este deporte comenzó a emerger en esta otra localidad como un deseo de ser futbolista, lo que lo ayudó a sostenerse en las prácticas y a tomar como referente adulto a su técnico.

\section{Volver a los 16}

Cuando Jonatan comenzó a asistir al centro de salud, dijo que tenía dieciséis años, al cumplir los supuestos diecisiete, expresó asombrado, ¡Cumplo dieciséis años! En algún momento Jonatan había perdido la cuenta.

¿Qué implica para un sujeto olvidar cuántos años tiene? Un equívoco, un fallido, pueden entrar a circular como interpretación en el momento de su autocorrección, en el momento de la negación, o en el momento donde quién escucha puede devolver algo del orden del dato preciso, un saber compartido. En esta situación, Jonatan decía su edad, y nadie lo ponía en duda, nadie lo interpelaba, no había otro allí que pudiera cumplir esa función. Él tenía la edad que decía tener. ¿Quién faltaba allí para decir otra cosa? Ningún niño pequeño puede llevar solo la cuenta de su edad. Eso ocurre recién a partir de determinado momento, cuando se incluye en una cronología compartida. Tampoco podemos saber aquí en qué momento Jonatan perdió la cuenta de su edad. Sabemos que los cumpleaños se festejan, aunque sea mínimamente, en el hogar, aunque no siempre. La pregunta no es solo por la realización o no de un ritual social compartido, sino por su efectividad en cuanto a marca subjetiva que permite diferenciar un antes y un después.

La historia singular y el tiempo se entrelazan. ¿Qué ha llevado a Jonatan a suponer que tenía dieciséis años cuando tenía quince?

¿La ausencia de un acto que lo ubicase adecuadamente en una línea cronológica? ¿La cantidad de acontecimientos por los que fue llevado aceleró los tiempos?

Jonatan no podía mencionar más que su sorpresa, y nada podía decir sobre esa diferencia. Intentamos ubicar aquí no solo la pérdida de la cuenta, o el armado de otra edad como si fuera la correcta, sino la falta de corrección por parte de los adultos, quienes lo acompañaban en ese sostenimiento de la edad. Jonatan cargaba con su edad, como lo hacía con su historia: solo. Y en esa 
soledad, que nunca es absoluta, cualquier pérdida o equívoco se arrastra hacia adelante, incluido el cronológico o temporal.

La historia singular, como la edad de cada sujeto, es relatada y sancionada por otro que tiene la capacidad de operar un corte en el devenir lineal y constante; pero, luego, la sanción se produce por el acto mismo del sujeto, interiorizando este otro, y pudiendo realizar marcas sobre su propia historia.

¿Qué lo llevó a Jonatan, en un determinado momento, a sumarse un año? ¿Qué lo llevó a alegrarse de ese equívoco?

En este punto cabe retomar dos cuestiones que se entrelazan. Por un lado, el paso del tiempo lo llevó a acercarse a los dieciocho años, punto en el cual queda por fuera de la lógica institucional, y a la vez, implicaba la llegada al momento en donde el futuro cobraría cierta certeza, sería decisivo. ¿Qué sucedería luego de ese momento donde ya la institución no reglamentaría su devenir? ¿Qué relato lo articula a Jonatsan en su dimensión temporal? Al decir de François Dosse (2013), la mediación indispensable para dar cuenta de la dimensión temporal se sitúa en la capacidad de hacer un relato. El tiempo solo llega a ser humano al articularse en un modo narrativo, así como el relato solo adquiere su verdadera dimensión cuando se estructura a partir de su dimensión temporal.

Este encuentro con su edad, en el marco del análisis, le permitió empalmar un relato en torno a una temporalidad, y recobrar discursivamente su edad. Esto advino con alegría en su sorpresa.

\section{Presencias y ausencias}

El vínculo familiar más fuerte y sólido que mantuvo afectivamente Andrés, y con quien pedía por momentos encontrarse, era con su hermana, quien quedó viviendo en Rosario, de centro residencial en centro residencial. Unos años mayor que él, esta adolescente, también reclamaba encontrarse con su hermano menor.

Dos equipos distintos tenían a su cargo las situaciones de estos hermanos, y los encuentros no pudieron realizarse, más que esporádicamente. Llegadas inesperadas, visitas canceladas a último momento, le servían al hogar donde se alojaba Andrés para remarcar la problemática del sostenimiento de los vínculos familiares. Más aún, teniendo en cuenta que estos encuentros producían en Andrés movimientos subjetivos importantes que lo llevaban a desorganizarse produciendo enojos y cambios de humor constantes.

En determinado momento, algo comenzó a aparecer en Andrés como situación repetitiva. Tempranamente señalado como mentiroso, Andrés relataba situaciones pasadas y presentes, interpretadas por los demás como inverosímiles. Su relato era sancionado y esperado como verdadero o falso. Estos relatos eran siempre llamativos, de gente que aparecía y solo él podía ver, a modo de espíritus. Veía objetos moverse y, luego de causar la impresión del otro, se echaba a reír diciendo "Ah, te lo creíste". ¿Cuál era el fundamento de los relatos de Andrés? Suponiendo que buscaba una impresión en el otro, ¿qué esperaba como devolución? En su gran mayoría, estos relatos no eran tenidos en cuenta más que como bromas, pero luego fue él quien empezó 
a escenificarlas escapándose del hogar, sin irse muy lejos, siempre dejándose encontrar. Podríamos construir una expresión que no dijo: "Ah, te creíste que no iba a volver". Cuando sus relatos dejaron de tener importancia para otro, fue él mismo, con su cuerpo, quien comenzó a representar las escenas desapareciendo, o representando escenas violentas, generando angustia frente a sus desapariciones al escaparse, o golpeando y rompiendo objetos en el hogar. Frente a estas situaciones, los referentes del hogar respondían con retos y penitencias.

Andrés tenía un lugar en la institución, pero sus relatos quedaban afuera. No eran incluidos, eran desacreditados. Sus palabras no eran oídas más que en la literalidad del momento, sin incluirlas en un relato que hablara de sí mismo, sin incluirlas en una historia de vida.

Lo único que él tomaba como posible en relación al reencuentro con su historia, era el contacto con su hermana, que por momentos lo suponía posible y por momentos, no. La experiencia de los encuentros llevados a cabo no le permitían rechazar por completo la posibilidad de volver a encontrarse, pero los constantes desencuentros y frustraciones generaban malestar, situación que lo dejaba prendido del otro, a la espera, como si, en reiteradas ocasiones, del otro retornara un "Ah, te lo creíste". Cada vez tenía que vérselas con la experiencia de que la hermana no iba a visitarlo. Las explicaciones variaban: el transporte no la podía llevar hasta esa localidad, el acompañante no pudo coordinar. En ocasiones, simplemente no sabían por qué su hermana no había llegado. Estas presencias y las ausencias aleatorias lo dejaban en una posición pasi- va, frente a la cual poco podía hacer. Sus bromas pueden pensarse como el intento de posicionarse activamente frente al otro y a la situación de inermidad en la que se encontraba.

\section{Andrés y su recuerdo repetitivo}

Andrés asistía a las sesiones regularmente, se divertía, jugaba, proponía juegos, planteaba una transferencia amistosa, lúdica, de pocos relatos. En algún momento comenzó con un relato escalofriante, pero sin que en su rostro y en su expresión se transmitiera algo relacionado a lo que contaba.

En su recuerdo apareció una escena de un tío "loco", que prendía fuego a un gato colgado de un alambre. Aclaró que él había estado presente en toda la escena, dando a entender su posición pasiva frente a esa escena siniestra. Pero si en el relato no mencionaba o expresaba angustia, ¿cómo se puede pensar si algo de lo traumático aconteció allí? Andrés volvía con esta escena una y otra vez. "¿Te conté de la vez que mi tío prendió fuego un gato?" Recuerdo que no asociaba con nada, parecía estar recortado de todo contexto.

Todo podía ser en la vida de Andrés y, quizás, no todo. A diferencia de Jonatan, quien podía decir una edad y tener otra, sin que nadie pudiera decir algo al respecto, Andrés podía construir-se historias, que podían pasar por verídicas, pero cuando esto iba del lado de lo increíble, se le devolvía la no-creencia y, frente a la expresión del otro, se retractaba. Varios años menor que Jonatan, buscaba insistentemente un lugar más preciso en el otro.

También como Jonatan, conservaba 
algo de su infancia, algo que insistía e intentaba una y otra vez que el otro lo tuviera en cuenta. La escena del tío prendiendo fuego un gato parecía querer recordar a su interlocutor y a sí mismo algo de otro lugar, algo de su historia previa a estar allí. Pero era, justamente, aquello que el otro tomaba y rechazaba a la vez, lo que el otro (no) podía escuchar, lo que hacía un hueco en el otro.

Cuando Andrés eligió a Jonatan como su padrino hizo algo particular. Por un lado, buscó a alguien muy cercano, que provenía al igual que él de Rosario, pero, a la vez, alguien que no pudo tomar ese lugar. Siguiendo a Beatriz Janin (2014), podemos pensar que cuando alguien siente que no tiene lugar ni espacio en la cabeza de los otros, que no hay proyecto ni cambio posible, queda reducido a una supervivencia en la que toda renuncia es renuncia al ser, por lo que no se puede pensar en heridas narcisistas, sino que éstas se confunden con la eliminación de sí mismo como sujeto. Andrés forzaba insistentemente hacerse un lugar en los demás como fuera posible, y por mucho tiempo se ubicó en el lugar que los otros le tenían asignado previamente, por lo que no podía más que adaptarse para sobrevivir.

\section{Reflexiones finales}

Los niños que, por haber tenido vulnerados sus derechos, son alojados en centros residenciales alejados de su territorio sociocultural, vuelven a ser vulnerados por el aparato institucional del Estado al hacerlos ingresar en una pasividad que no les permite ser partícipes de las decisiones que implican grandes cambios en sus vidas.

La referencia a sus familias no se anula totalmente, sino que en esta puja entre la Dirección de Niñez que intermitentemente produce encuentros con algún familiar y la posición de la institución de alojamiento de no apoyar esa revinculación, se produce un quedar a la espera de un retorno sin la posibilidad de una anticipación estable.

La espera pasa de ser expectante, a transformarse en una cristalización de un presente. No se conforman identidades en espera, sino que se vuelve una espera sin identidad.

A partir del momento en que ingresan al hogar, comienza un entramado de reacomodaciones y adaptaciones a la que los niños se ven obligados a introducirse si es que aceptan la hospitalidad y los límites que estas instituciones les ofrecen. La pasividad, teniendo en cuenta la imposibilidad de participar de la decisión por su devenir, implica que el corte devenga traumático en relación a la dependencia de las intervenciones estatales o institucionales. Este corte separa un antes y un después tajantes, que no le permiten a estos niños realizar una elaboración simbólica a modo de tránsito de un momento a otro. Por tanto, ese trabajo queda para un tiempo posterior impreciso $y, a$ veces, imposible.

Luego de un lapso de tiempo en estas instituciones, pudimos ver que el pasado de los niños comienza a quedar relegado de su discurso, aunque no por ello ausente en sus síntomas y emergencias esporádicas. Cuando un otro se sostiene en una escucha que no intenta direccionar el decir de los niños, se hace presente la posibilidad de que puedan hilvanarse relatos pertenecientes tanto a su pasado como a su presente, desplegando una elaboración simbólica que dé lugar a la construcción de un futuro. Esto es con 
lo que nos encontramos dentro del espacio clínico después de instalada una relación transferencial que permitió el despliegue discursivo de lo que se callaba en otros lugares.

Los efectos subjetivos de la deprivación (Winnicott, 2013) partieron, en la elaboración, hacia dos instancias que confluyen: por un lado el distanciamiento, noción que remite a un pasado y, por otro lado, un presente que no siempre tiene en cuenta la historia singular de cada niño. Esto conlleva que los lazos no posean la estabilidad que posibilita una elaboración identitaria, como totalidad aparente en la que un sujeto puede nombrarse frente a otro, sino que van produciéndose identificaciones fragmentarias que no tienen en cuenta lo que el niño o adolescente porta de manera innombrable.

Para permanecer alojados en esta institución, los niños silencian su pasado. Lo que en ese silencio se oculta, es lo que la institución no puede escuchar, y esto está relacionado con el lugar del cual provienen estos niños. Queda subyacente, así, una lógica de anulación, siempre fallida, de lo que los llevó a estar apartados de sus lazos familiares. Pero si pensamos que la anulación del pasado es siempre fallida, es porque en algún punto esto vuelve a emerger, y ese momento no es solo en el cual tienen que vérselas con la salida de esa institución, cuando la historia reaparece sin velo, sin un entramado cronológico en una coagulación presente, sino que emerge, también, en los momentos donde una referencia a su historia silenciada ingresa en la cotidianeidad.

Podemos describir dos modos en que las significaciones relacionadas a su pasado se hacen presente. Por un lado, como elaboraciones sintomáticas que, al modo del retorno de lo reprimido, encuentran la forma de expresarse $y$, en otras circunstancias, el pasado retorna sin la elaboración propia de los avatares de la represión, como pasaje al acto que emerge en un presente absoluto, sin historización.

La etapa donde indefectiblemente tienen que enfrentarse a su futuro, donde una elección podría devenir posible, es en la cual la historia anulada en el discurso del otro emerge del lado del sujeto abruptamente, sin el velo que la función del relato implica. En la emergencia de la conjunción de los tiempos del recordar y el elegir, en la anulación e imposibilidad de separar estas dos instancias, el pasaje al acto aparece como la marca de la borradura, el recordar se hace presente en el actuar, y las herramientas de las cuales se dispone son aquellas que quedaron sin elaboración.

Encontramos en el lenguaje un modo de resistencia frente a la deprivación y la consecuente anulación de la historia de los niños. Cuando un detalle lingüístico los devuelve como no formando totalmente parte de la localidad que los recibe, encuentran allí un mecanismo para poder nombrarse haciendo diferencia con un otro que en ocasiones no les permite construir una imagen especular atravesada por la diferenciación que implica la ley.

Frente a la doble significación que cobra la ruptura con su pasado, pudimos ver que el trabajo psíquico más costoso para estos niños es el de sostener, a pesar del otro, una identidad, como resistencia frente a la negación proveniente del adulto referente.

En estas situaciones, no solo se distor- 
sionan las referencias culturales que hacen a la identidad de un niño o adolescente, sino que el modo de insertarse de un sujeto en una cronología llega a ser también problemático, por no contar con un otro que pueda hablarle comenzando la historia desde un inicio compartido. La edad de estos niños no hace referencia al momento en el cual llegaron al hogar, sino que es la referencia más directa a un tiempo previo a la aplicación de la medida excepcional. En muchas situaciones es mayor el tiempo de vida que pasan en los hogares que el que transcurrieron con sus familias.

Los efectos subjetivos que atraviesan los niños y adolescentes atravesados por la aplicación de una medida de protección excepcional, implican la conmoción de sus identidades, la negación de su historia por parte del otro y la consecuente dificultad de proyectar un futuro en compañía de un referente adulto. Debido a esto, en determinados momentos, la historia silenciada reaparece, no como herramienta para construir un futuro, sino que a falta de un proceso de simbolización y apropiación de su propia historia, el pasado se confunde con el presente, emergiendo de manera desarticulada.

\section{Bibliografia}

- Dosse, F. (2003) La Historia: Conceptos y Escrituras. Buenos Aires: Nueva Visión.

- Janin, B (2014), Niños y Adolescentes en situación de Vulnerabilidad. En Cuestiones de infancia, $\mathrm{N}^{\circ} 16$. Universidad de Ciencias Empresariales y Sociales. Pp.23/33. Disponible en http://dspace.uces.edu.ar:8180/xmlui/ bitstream/handle/123456789/2525/Ninos_Janin.pdf?sequence $=1$ Fecha de recuperación: 2016

- Ley 12.967. Legislatura de la provincia de Santa Fe, Santa Fe, Argentina, 17 de abril de 2009.

- Winnicott, D. (2013) Deprivación y delincuencia. Buenos Aires: Paidos. 